\title{
A von Hamos spectrometer based on highly annealed pyrolytic graphite crystal in tender x-ray domain
}

Cite as: Rev. Sci. Instrum. 92, 073104 (2021); https://doi.org/10.1063/5.0054421

Submitted: 18 April 2021 • Accepted: 01 July 2021 • Published Online: 15 July 2021

lyas Ismail, Loïc Journel, Régis Vacheresse, et al.

\section{ARTICLES YOU MAY BE INTERESTED IN}

High resolution $\mathrm{x}$-ray emission spectrometer for multiple hard $\mathrm{x}$-ray emission lines:

Demonstration for $\mathrm{Cu} \mathrm{Ka}$ and $\mathrm{K} \beta$ emissions

Review of Scientific Instruments 92, 073105 (2021); https://doi.org/10.1063/5.0048726

Extension of single-crystal $\mathrm{x}$-ray spectropolarimetry with cubic crystals beyond perfect polarization-splitting geometries

Review of Scientific Instruments 92, 073102 (2021); https://doi.org/10.1063/5.0047035

Projection-type electron spectroscopy collimator analyzer for charged particles and x-ray detections

Review of Scientific Instruments 92, 073301 (2021); https://doi.org/10.1063/5.0051114

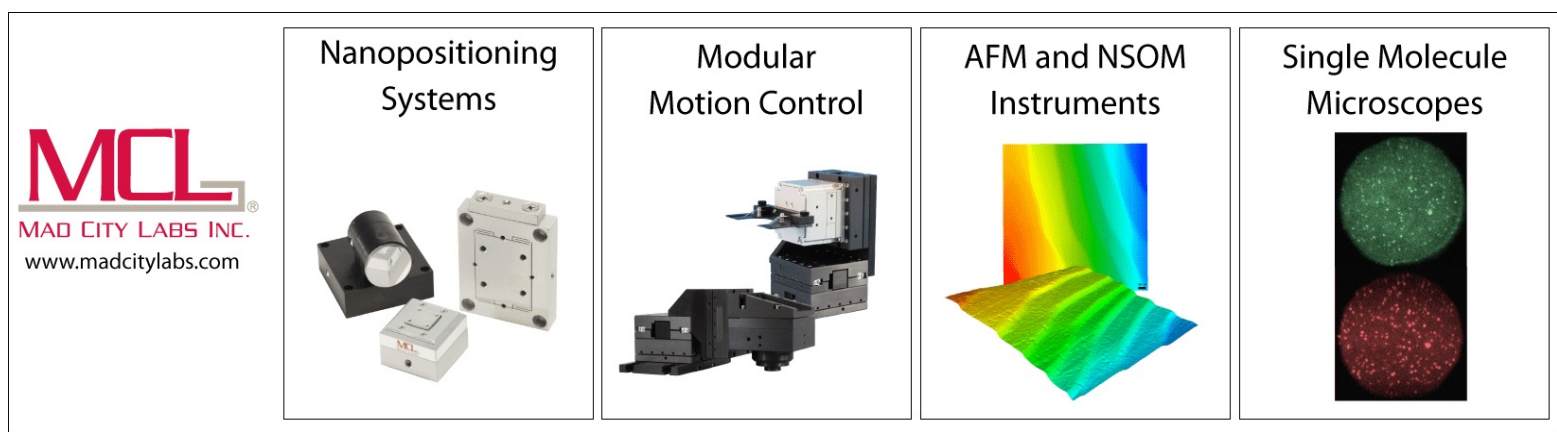




\title{
A von Hamos spectrometer based on highly annealed pyrolytic graphite crystal in tender $\mathbf{x}$-ray domain
}

Cite as: Rev. Sci. Instrum. 92, 073104 (2021); doi: 10.1063/5.0054421

Submitted: 18 April 2021 - Accepted: 1 July 2021 •

Published Online: 15 July 2021

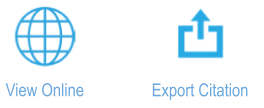

Iyas Ismail,, a) (D) Loïc Journel, Régis Vacheresse, ${ }^{1}$ Oksana Travnikova, ${ }^{1}$ Thierry Marin, ${ }^{1}$ Denis Céolin, ${ }^{2}$

Renaud Guillemin, ' Tatiana Marchenko,' Moustafa Zmerli, ' Dimitris Koulentianos, , ${ }^{1, b)}$ (D) Ralph Püttner,

Jérôme Palaudoux, 'Francis Penent, ${ }^{1}$ (D) and Marc Simon' (D)

\begin{abstract}
AFFILIATIONS
'Sorbonne Université, CNRS, UMR 7614, Laboratoire de Chimie Physique-Matière et Rayonnement, 4 Place Jussieu, 75252 Paris, France

${ }^{2}$ Synchrotron SOLEIL, I'Orme des Merisiers, Saint-Aubin, BP 48, F-91192 Gif-sur-Yvette Cedex, France

${ }^{3}$ Fachbereich Physik, Freie Universität Berlin, Arnimallee 14, D-14195 Berlin, Germany
\end{abstract}

\author{
a) Author to whom correspondence may be addressed: iyas.ismail@upmc.fr \\ b) Present address: Chemical Sciences and Engineering Division, Argonne National Laboratory, 9700 S Cass Avenue, \\ Lemont, IL 60439, USA.
}

\begin{abstract}
We have built an x-ray spectrometer in a von Hamos configuration based on a highly annealed pyrolytic graphite crystal. The spectrometer is designed to measure $\mathrm{x}$-ray emission in the range of $2-5 \mathrm{keV}$. A spectral resolution $\mathrm{E} / \Delta \mathrm{E}$ of 4000 was achieved by recording the elastic peak of photons issued from the GALAXIES beamline at the SOLEIL synchrotron radiation facility.
\end{abstract}

Published under an exclusive license by AIP Publishing. https://doi.org/10.1063/5.0054421

\section{INTRODUCTION}

The recent development of $\mathrm{x}$-ray sources, as third and fourth generation synchrotrons or x-ray free electron lasers (XFELs), has opened opportunities for investigating new phenomena by means of photoelectron and Auger spectroscopies, electron-ion coincidence techniques, and x-ray emission. ${ }^{1-6}$ Several processes of high scientific interest are still difficult to measure. This is the case, for instance, of radiative Auger emission ${ }^{7}$ and Resonance-Enhanced X-ray Multiple Ionization (REXMI) ${ }^{8}$ that would both require the detection of photons not only with high efficiency and resolution but also in coincidence with ions or electrons. It is also the case for the investigation of very low cross section phenomena such as attosecond electron dynamics $^{2}$ and high-energy resolution off-resonant spectroscopy (HEROS). ${ }^{9,1}$

High-resolution $\mathrm{x}$-ray spectroscopy in the hard $\mathrm{x}$-ray energy domain is typically performed with crystals working on a Bragg diffraction basis. In order to increase the collection efficiency of $\mathrm{x}$ rays, single or multiple bent crystals can be used in different geometries. Based on the way the spectrum is collected, one can distinguish two main classes of spectrometers. The first one uses point-to-point focusing, meaning that the collection of the different energies requires scanning of both the crystal and the detector. This is the case of most of Johann ${ }^{11}$ and Johansson ${ }^{12}$ spectrometers, which allow achieving a very high resolution. The second class uses a "point to segment" focusing scheme, where a single-shot spectrum is recorded without using any moving elements. This is the case of von Hamos geometry ${ }^{13}$ that uses a cylindrically bent crystal that focuses $\mathrm{x}$ rays along its curvature axis while dispersing the photons along its flat side, similar to a flat crystal. The dispersed photons are recorded with a position sensitive detector, allowing the simultaneous measurement of different energies to obtain the spectrum. It is noteworthy to mention that such a dispersive scheme has been realized using Johann geometry with a source located inside the Rowland circle. ${ }^{14,15}$ von Hamos geometry presents a good compromise between efficiency and resolution without any scanning element. ${ }^{16,17}$ It can record a single-shot wide-range (several tens of eV) spectrum with high efficiency, allowing consideration of the possibility of 
coincidence measurements. This is why this geometry is very convenient for work at large scale facilities as synchrotrons, XFELs, and heavy ion accelerators and with laboratory sources. In addition, it is also very advantageous for time-resolved studies.

An x-ray spectrometer can be equipped with mosaic or perfect crystals. Perfect crystals such as $\mathrm{Si}$ (111), LiF (200), or Ge (111) are commonly used in $\mathrm{x}$-ray fluorescence (XRF) analysis since they allow high spectral resolution, but with a rather limited reflectivity. In contrast, mosaic crystals have higher reflectivity, ${ }^{18}$ which promote them as the best candidates for applications requiring high collection efficiency. For instance, X-ray Oriented Programs (XOP) ${ }^{19}$ calculations predict an order of magnitude gain in the integral reflectivity of the graphite mosaic (002) crystal relative to the $\mathrm{Si}$ (111) crystal at $2300 \mathrm{eV}$ photon energy. Recently, graphite mosaic crystals have been used with success in von Hamos geometry to measure $\mathrm{x}$ rays in the range of $4.5-10 \mathrm{keV}^{18,20}$ and $8-60 \mathrm{keV}^{21}$ as well as in the range of $5-15 \mathrm{keV}^{22}$ with a resolving power of about 2000.

In this large context, we have developed a new von Hamos spectrometer working in the energy range of $2-5 \mathrm{keV}$, at the first order of reflection, with a resolution better than $1 \mathrm{eV}$ over the entire energy range. Indeed, a higher order of reflection can be used to detect photons of higher energy. This spectrometer has a high transmission owing to the use of a large mosaic crystal. This will enable investigation of low cross section phenomena at the K-edge of elements from phosphor to vanadium and the L-edge of elements from zirconium to platinum. This spectrometer will be also well suited to study chemistry of sulfur compounds, which is of great interest for battery development. ${ }^{23}$ The description of this instrument as well as the first results of its characterization is presented here.

\section{DESIGN: THE VON HAMOS SPECTROMETER WITH AN HAPG CRYSTAL}

von Hamos geometry consists of using a cylindrically curved crystal (around the $\mathrm{z}$-axis in Fig. 1). In the XY-plane, the crystal focuses the diffracted $\mathrm{x}$ rays on the $\mathrm{Y}$-axis of the detector, when both the detector and the $\mathrm{X}$-ray source are placed at the axis of the curvature of the crystal. In the XZ-plane, called the dispersive plane, the crystal acts as a flat crystal. Photons of different energies are diffracted at different angles according to the Bragg law,

$$
n \frac{h c}{E}=2 d \sin \left(\Theta_{B}\right)
$$

where $n$ is the diffraction order, $h$ is the Planck constant, $c$ is the light velocity, $E$ is the photon energy, and $d$ is the crystal lattice spacing.

The energy spectrum is obtained by measuring the position of the diffracted photons on the detector. The central Bragg angle $\Theta_{B}$ is defined by the position of the detector and the source along the $\mathrm{z}$ axis. It is noteworthy to mention that, in the von Hamos geometry, the distance $L$ (see the inset of Fig. 1) between the source and the crystal and that between the crystal and the center of the detector are identical and equal to $R / \sin \left(\Theta_{B}\right)$, with $\mathrm{R}$ being the curvature radius of the crystal.

A mosaic graphite crystal has been chosen because of its high integrated-reflectivity; moreover, it allows working at the first order of reflection in the energy range $2-5 \mathrm{keV}$. The mosaic crystal consists of many micro-size (or even sub-micro) perfect crystals oriented quasi-parallel to each other. The angular deviation from the

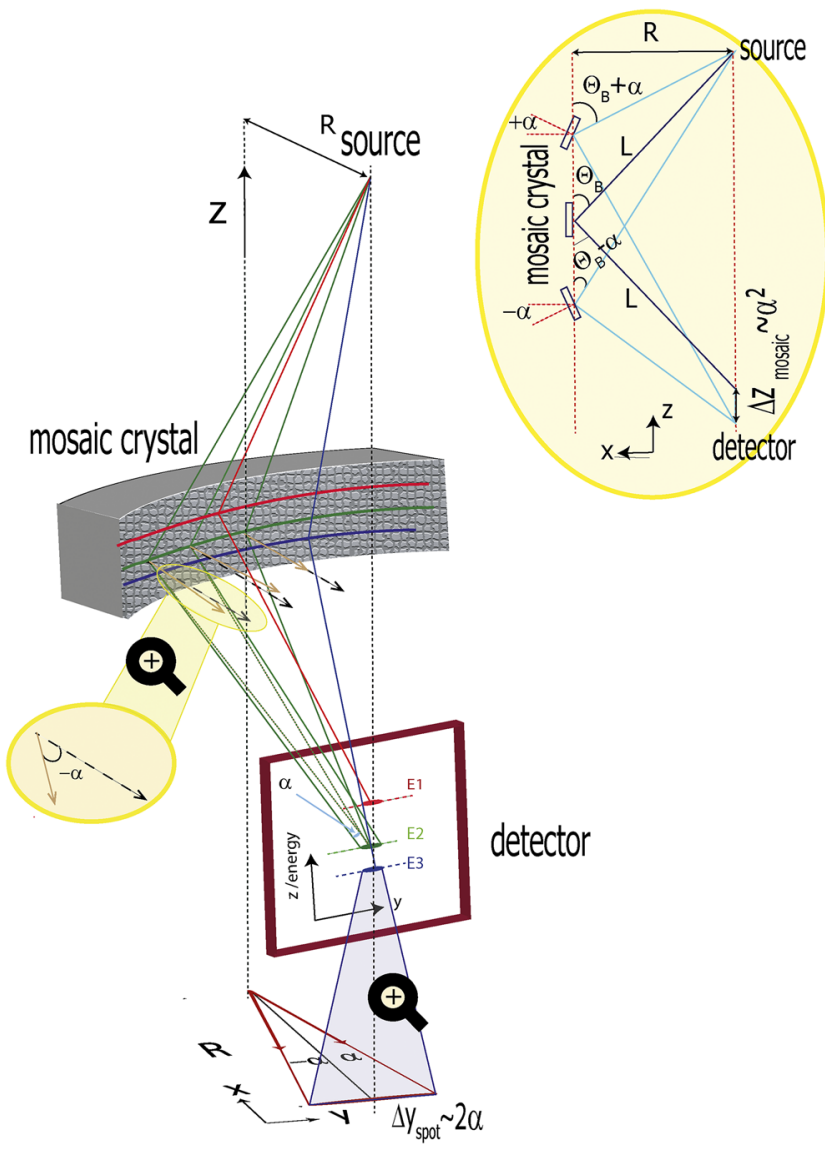

FIG. 1. Schematic of a mosaic HAPG crystal in von Hamos geometry. Photons of different energies (colors) are diffracted with different Bragg angles to different positions on the detector. The z-axis (on the detector) is directly related to the photon energy by the spectrometer dispersive coefficient [Eq. (5)]. In the XY-plane, in the first order, the curved crystal focuses the emitted photons to the center of the detector. The use of the mosaic crystal introduces an angular divergence of $2 \alpha$, which causes a broadening ( $\left.\Delta y_{\text {spot }}\right)$ of the spot on the y-axis (shown at the bottom). In the dispersive plane, a semi-focusing effect of the mosaic crystal occurs. In fact, the Bragg law imposes a certain focusing of the diffracted photons into a small segment $\Delta \mathrm{z} \sim \alpha^{2}$ (dispersive axis), only if the source-crystal and crystal-detector distances are equal (shown at the top).

perfect-parallelism is characterized by the mosaic spread $2 \alpha$, which is the full width at half-maximum (FWHM) of this angular distribution. The direct consequence of mosaicity is a larger integrated reflectivity than perfect crystals. Among mosaic graphite crystals, Highly Annealed Pyrolytic Graphite (HAPG) has been selected since it can be produced with lower mosaicity spread (as low as $0.05^{\circ}$ ) than other most-commonly used mosaic Highly Oriented Pyrolytic Graphite (HOPG) crystals (typically $0.4^{\circ}-1.2^{\circ}$ ). This choice allows higher energy-resolution and minimizes focal aberrations.

HAPG is an artificial graphite (for details, see, for example, Ref. 24) with a lattice spacing $2 \mathrm{~d}$ (002) of $6.708 \AA$ A. Our crystal was developed by Optigraph GmbH (Berlin, Germany). The HAPG crystal can be fabricated as thin flexible sheets of desired thickness that can 
be deposited on a substrate of almost any shape (see, for instance, Ref. 25).

A curved HAPG crystal of a $=25 \mathrm{~mm}$ along the dispersive direction and $b=110 \mathrm{~mm}$ (in the non-dispersive direction) with a radius of curvature $\mathrm{R}=500 \mathrm{~mm}$ has been built. The substrate is made of $\mathrm{N}$ BK7 glass and coated with an HAPG layer ( $40 \mu \mathrm{m}$ thickness) by the Optigraph company. When operating at a Bragg angle of $67.5^{\circ}$, an energy range of $35 \mathrm{eV}$ is covered by the analyzer with a solid angle of $10 \mathrm{msr}$. This corresponds to a solid angle per energy of $0.29 \mathrm{msr} / \mathrm{eV}$. The spectrometer can cover Bragg angles between $20^{\circ}$ and $67^{\circ}$ corresponding to an energy domain of $5400-2000 \mathrm{eV}$ at the first order of reflection.

A new homemade $\mathrm{x}$-ray detector based on the combination of microchannel plates and a special type of photocathode has been used. ${ }^{26}$ Its detection efficiency and time response are crucial for the purpose of coincidence measurements with ions or electrons. The spectrometer was operated under a vacuum condition of $<1.010^{-6}$ mbar.

\section{CHARACTERIZATION}

\section{A. Mosaic spread estimation}

The mosaic crystal increases the efficiency but introduces aberrations and defocusing effects. In the XY-plane, the angular distribution of the mosaic crystal causes defocusing $\left(\Delta y_{\text {spot }}\right)$ (see Fig. 1), which depends on the mosaic spread $(2 \alpha)$ [Eq. (2)]. This is not critical neither for the efficiency, since we use a large 2D detector, nor for the energy resolution. In the dispersion plane (XZ-plane), the mosaic crystal has a semi-focusing effect of the $\mathrm{x}$ rays under the condition that the distances between the source and the crystal and between the crystal and the detector are equal. This condition ensures to reduce the broadening along the $\mathrm{Z}$ dispersion axis to $\Delta \mathrm{z} \sim \alpha^{2}$ and consequently minimizes the energy broadening caused by the mosaic distribution of the crystal. ${ }^{27}$ Any deviations on these distances can directly affect the spectral resolution.

The mosaic spread can be measured, using a source of welldefined (or of very small) dimension, by examining the defocusedspot along the non-dispersive $\mathrm{Y}$-axis. The mosaic spread $(\alpha)$ can be, therefore, obtained from the FWHM of the defocused-spot $\Delta y_{\text {spot }}$ by the expression

$$
\alpha=\operatorname{acrtan}\left(\left(\triangle y_{\text {spot }}-s_{1}\right) / 2 R\right),
$$

where $s_{1}$ is the dimension of the source along the $y$-axis.

This measurement was performed by the manufacturer (Optigraph) using $\mathrm{Cu} \mathrm{K} \alpha$ lines, with $s_{1}=13.7 \mu \mathrm{m}$. Its mosaic spread was measured to be $\alpha=0.057^{\circ}$.

\section{B. Energy resolution}

The energy resolution of the spectrometer has two main contributions: geometrical and intrinsic. The geometrical one depends on the experimental conditions (the size of the source and the orientation) and the detector resolution, while the intrinsic contribution is specific to the crystal characteristics. The latter comprises mainly the broadening associated with the stress induced in the lattice planes due to the crystal bending $\left(\Delta \mathrm{E}_{\text {bend }}\right)$ and that of the mosaicity of the crystal.

\section{Intrinsic contribution}

$\Delta \mathrm{E}_{\text {bend }}$ depends on the Poisson ratio of the crystal, the penetration depth of $\mathrm{x}$ rays, and the bending radius (for more details, see Ref. 28). For graphite, the Poisson ratio is 0.2 , which roughly corresponds to $\Delta \mathrm{E}_{\text {bend }}=0.075$ at $3300 \mathrm{eV}$. This evaluation should only be considered as a rough estimation of this broadening and must be verified experimentally.

As long as the condition of equal source-crystal and crystal-detector distance is respected, the semi-focusing effect of the mosaic crystal takes place, and the energy broadening $\Delta E_{\text {Mosaic }}$ is reduced to $\Delta E_{\text {Mosaic }} / E=\left(\alpha / \tan \left(\Theta_{B}\right)\right)^{2}$. With $\alpha=0.057^{\circ}$ and $\Theta_{B}=34.06^{\circ}$, we find $\Delta E_{\text {Mosaic }}=0.01 \mathrm{eV}$ for an energy of $3300 \mathrm{eV}$, i.e., this contribution is negligible.

\section{Geometrical contribution}

The geometrical contributions can be understood as an angular deviation from the exact Bragg angle. It can be derived from the Bragg formula as the following expression:

$$
\begin{gathered}
\Delta E_{G} / E=\Delta \Theta / \tan \left(\Theta_{B}\right), \\
\Delta \Theta^{2}=\Delta \Theta_{S}{ }^{2}+\Delta \Theta_{D}{ }^{2} .
\end{gathered}
$$

$\Delta \Theta$ summarizes any angular deviation from the exact Bragg angle. ${ }^{29}$ $\Delta \Theta_{S}=s_{2} / \mathrm{OP}$ is the angular divergence in the plane of diffraction caused by the finite source size $s_{2}$ along the dispersion direction $\mathrm{Z}$. $\Delta \Theta_{D}=D / O P$ is the angular divergence limited by the spatial resolution of the detector D. OP $=2 \mathrm{R} / \sin \left(\Theta_{\mathrm{B}}\right)$ is the optical path length between the sample and the detector.

The main contribution to the energy resolution of the spectrometer is actually dominated by the geometrical broadening. The spatial resolution of the detector, equal to $100 \mu \mathrm{m}$, gives rise to $\Delta E_{D}=0.28 \mathrm{eV}$. The width of the source, along the dispersing direction, contributes significantly to the spectral resolution.

We have carried out a series of measurements to determine the overall resolution of the spectrometer. Two methods were used to determine the resolution and the dispersion curve of the spectrometer using the synchrotron radiation source.

\section{Elastic peak}

The elastic peak broadening depends only on the photon bandwidth of the beamline and the spectrometer resolution. In Thomson (elastic) scattering, the energy of the scattered photon is equal to the energy of the incident photon. An Fe sample was placed (in air) at the focal point of the GALAXIES beamline of the SOLEIL synchrotron. ${ }^{30}$ The beam dimensions at the focus point are $30(\mathrm{~V})$ $\times 80(\mathrm{H}) \mu \mathrm{m}^{2}$. A large window $(120 \mathrm{~mm}$ diameter and made of thin aluminized-Mylar consolidated by a laminar support) was installed at the entrance of the spectrometer chamber.

The sample, the crystal, and the detector were set in the vertical plane at $45^{\circ}$ with respect to the incoming beam. The elastic peak was recorded for several incident energies around $5900 \mathrm{eV}$ at the second order reflection and with a central Bragg angle $\Theta_{B}=38.67^{\circ}$. The distance between the sample and the crystal (and between the crystal and the detector) was set to $800.2 \mathrm{~mm}$.

Figure 2 shows the 2D image of two elastic peaks separated by $2 \mathrm{eV}$. These peaks, corresponding to excitation energies 5912 and 


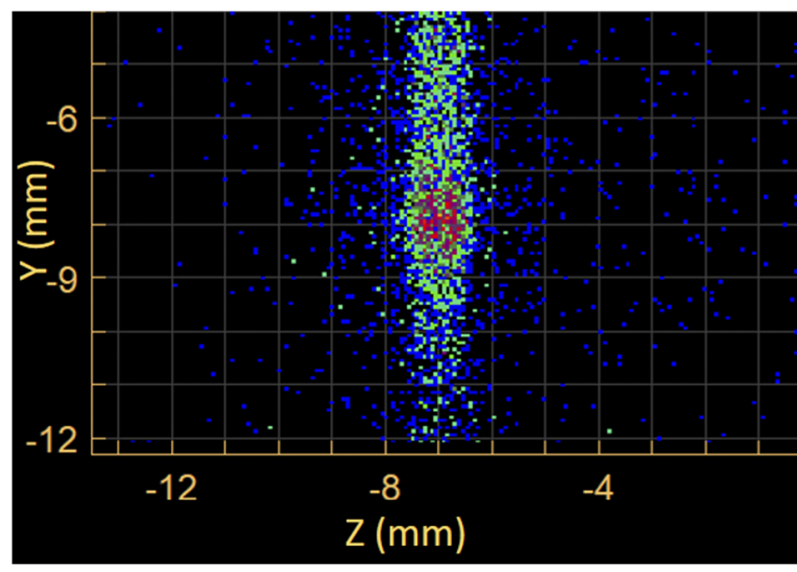

FIG. 2. Raw image obtained by measuring two elastic peaks recorded at 5912 and $5914 \mathrm{eV}$ photon energies.

$5914 \mathrm{eV}$, were recorded by changing the energy of the photon beam during the acquisition. The corresponding spectrum (Fig. 3) was obtained by projection of the 2D image along the dispersion axis and converted into an energy scale as explained in Sec. III D 3. Assuming a Gaussian distribution of the photon bandwidth, the spectrum was fitted with two Gaussian functions with the same FWHM width of $1.70 \pm 0.03 \mathrm{eV}$. This width incorporates the photon bandpass of the beamline (0.85@6000 eV) and the instrumental function of the spectrometer. After deconvolution of the beamline contribution, this results in a spectrometer resolution of $1.47 \mathrm{eV}$ corresponding to a resolving power of $\mathrm{E} / \Delta \mathrm{E}=4000$.

It is noteworthy to mention that the focal aberrations, which can be observed in Fig. 2 (and also in Fig. 4), are mainly caused by

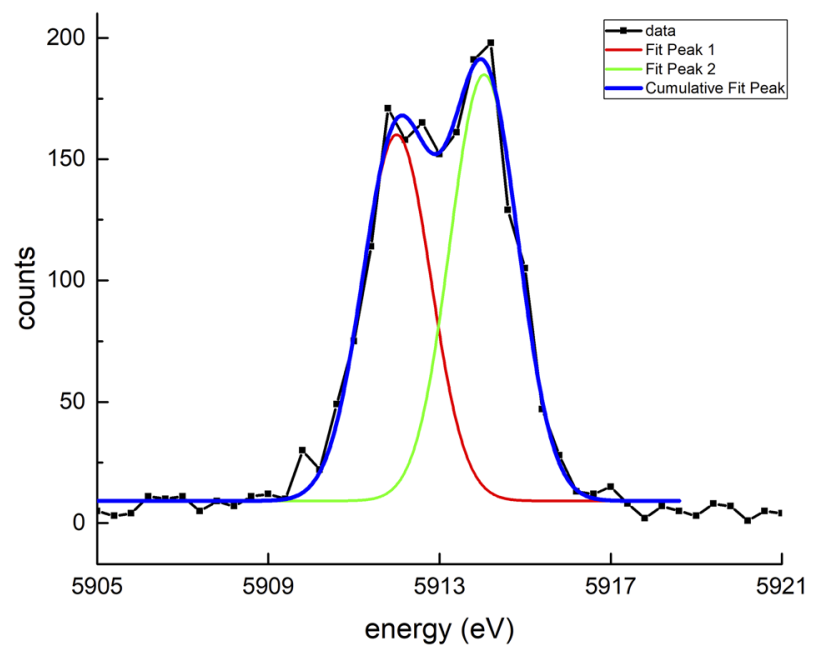

FIG. 3. Spectrum corresponding to two elastic peaks separated by $2 \mathrm{eV}$. It was obtained by the projection of the $2 \mathrm{D}$ image (Fig. 4) along the dispersion axis and converted into an energy scale.

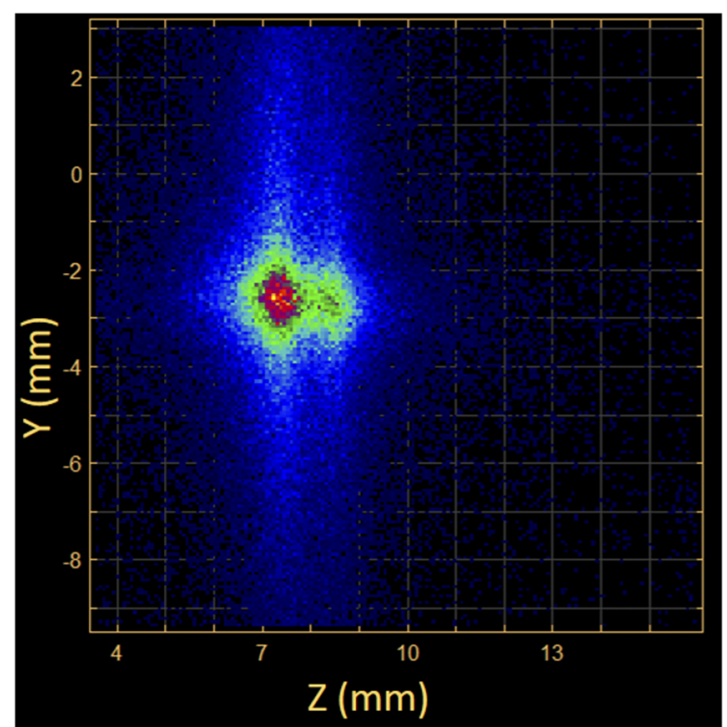

FIG. 4. Raw image corresponding to potassium $\mathrm{K} \alpha$ emission produced by irradiation of the $\mathrm{K}$ sample with $5 \mathrm{keV}$ photons.

the mosaic spread and the large aperture of the crystal as reported in Ref. 31 , in addition to eventual mechanical misalignments.

It should be mentioned that a resolving power of $\sim 8000$ was recently reported by Abraham et al. ${ }^{32}$ using a lithium niobate crystal in von Hamos geometry. $\mathrm{XOP}^{19}$ calculations show that the integral reflectivity of the graphite mosaic (002) crystal is three times higher than that of the $\mathrm{LiNbO}_{3}(01 \overline{4})$ crystal at $2300 \mathrm{eV}$.

\section{Potassium Ka}

In order to confirm the resolving power value obtained using the elastic peak, we measured the fluorescent $K \alpha$ potassium emission induced by the irradiation of the solid $\mathrm{K}$ sample by photons of $5 \mathrm{keV}$ issued from the GALAXIES beamline of the SOLEIL synchrotron. The sample was placed at a distance of $2 \mathrm{~m}$ from the focus point of the beamline. Figure 4 shows the $2 \mathrm{D}$ image corresponding to the potassium $\mathrm{K} \alpha$ emission measured with a (central) Bragg angle $\Theta_{B}=33.9^{\circ}$; the distance $L$ is $896.5 \mathrm{~mm}$.

Figure 4 shows a raw image corresponding to the measured potassium $\mathrm{K} \alpha$ emission. The emission spectrum (Fig. 5) is obtained by the projection of this $2 \mathrm{D}$ image onto the $\mathrm{z}$-axis of the detector. Potassium $\mathrm{K} \alpha$ emission has two main contributions: $\mathrm{K} \alpha_{1}=3313.8 \mathrm{eV}$ and $\mathrm{K} \alpha_{2}=3311.1 \mathrm{eV}$. A third less-intense contribution $\left(\mathrm{K} \alpha^{\prime \prime}\right)$ is observed and has been already assigned by Kawai et al. to the transition $1 s^{-1} 3 p^{-2} \rightarrow 2 p^{-1} 3 p^{-2}$ and found to be particularly sensitive to the chemical environment. ${ }^{33}$

The obtained spectrum is the convolution of three lines with the instrumental function. Three Voigt functions having the same Gaussian width and Lorentzian width of $0.89 \mathrm{eV}^{33,34}$ corresponding to $\mathrm{K} \alpha_{1}$ and $\mathrm{K} \alpha_{2}$ contributions were used to fit the spectrum. A Gaussian width (FWHM) of $1.70 \mathrm{eV}$ was deduced from the fit. This width represents the overall instrumental resolution including (mainly) the broadening caused by the relatively large source height (the measurement was performed out of the beam focus). This value 


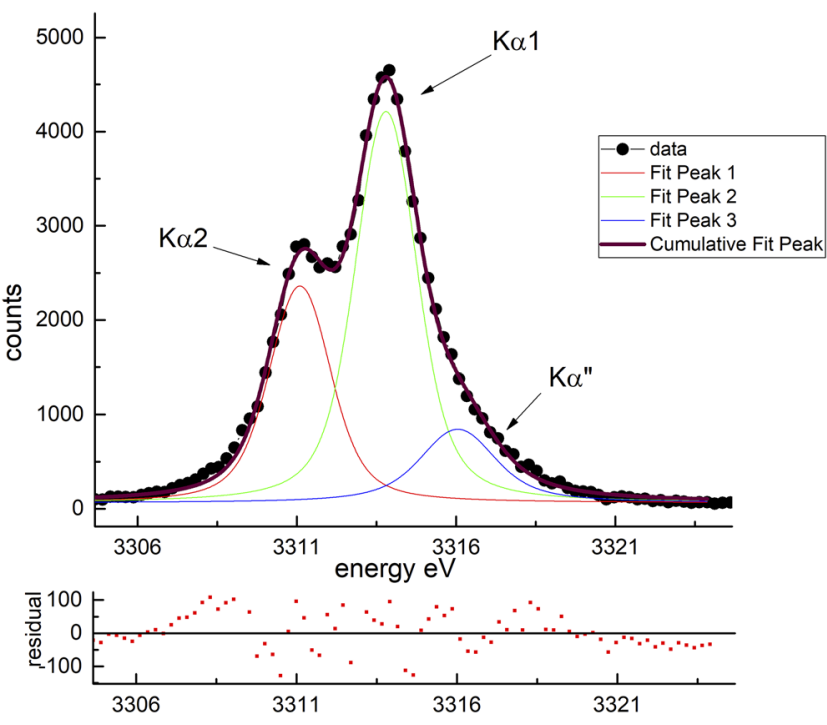

FIG. 5. Potassium $\mathrm{K} \alpha$ emission spectrum obtained by projection of the $2 \mathrm{D}$ image along the dispersion axis and changing to an energy scale as explained in Sec. III D 3. The spectrum has been fitted with three Voigt functions (see text for details). The residual of the fit is plotted at the bottom.

is compatible with the resolving power, measured by elastic peak, after taking into account the $1.5 \mathrm{eV}$ energy broadening due to the source height.

\section{Energy calibration}

The spectrometer has been calibrated by recording the elastic peak at different incident energies. The energy was changed with a

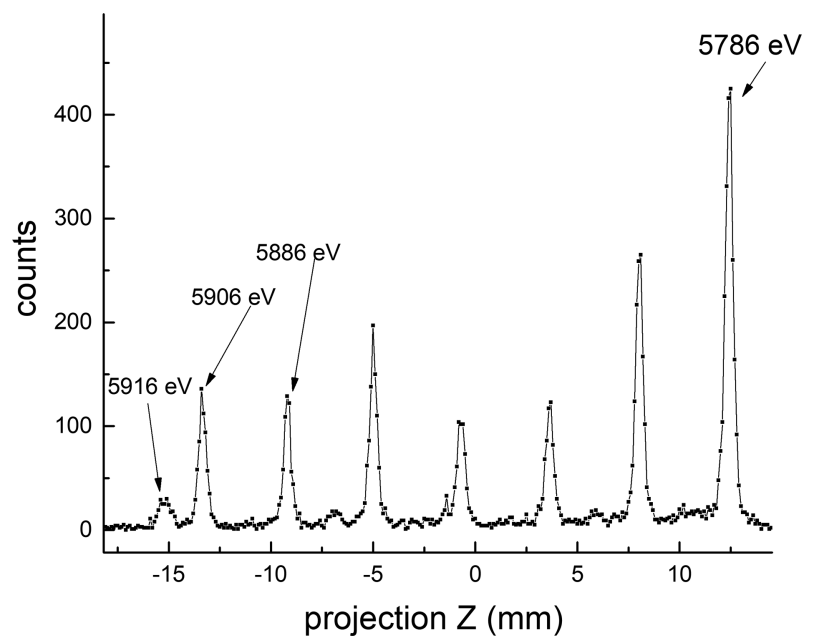

FIG. 6. Spectrum obtained by measuring elastic peaks. The energy of the beam was changed during the acquisition with a step width of $20 \mathrm{eV}$ from 5786 to $5906 \mathrm{eV}$ and of $10 \mathrm{eV}$ for the last point at $5916 \mathrm{eV}$. It should be noted that the intensity variations are due to different accumulation times during the measurement.

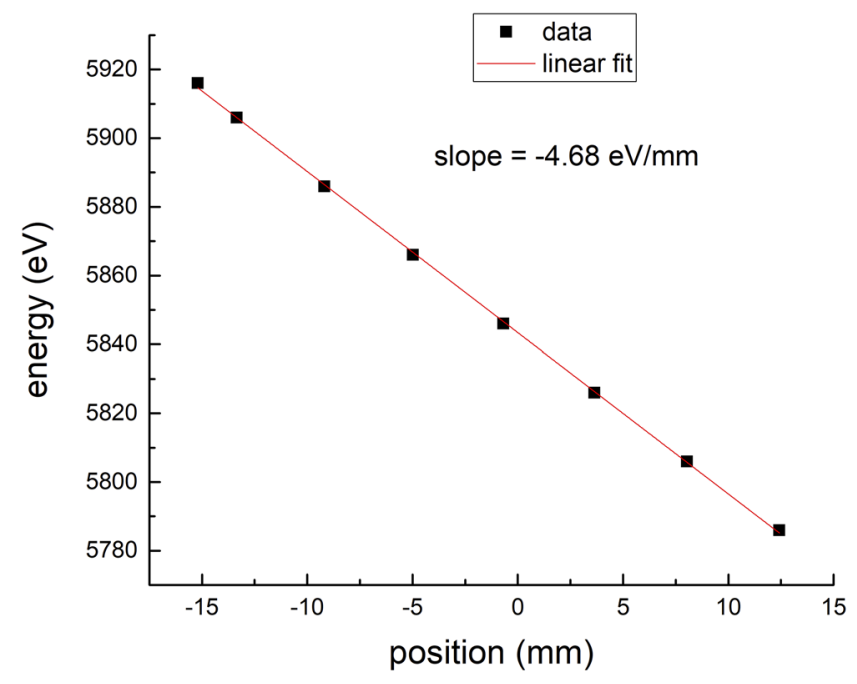

FIG. 7. Dispersion curve obtained by plotting the incident photon energy as a function of the position $Z$ of the peak maximum (from Fig. 6). The points were fitted with a linear equation with a slope of $-4.68 \mathrm{eV} / \mathrm{mm}$.

step width of $20 \mathrm{eV}$ between 5786 and $5906 \mathrm{eV}$ and with $10 \mathrm{eV}$ for the last point at $5916 \mathrm{eV}$. The projection of the detector image on the dispersion axis is shown on Fig. 6.

From the data plotted in Fig. 6, the position $\mathrm{Z}$ (in $\mathrm{mm}$ ) for the maximum of each elastic peak maximum is deduced. Figure 7 shows the energy of each elastic peak as a function of this position $\mathrm{Z}$. A linear relationship between the incident energy and the position $\mathrm{Z}$ is obtained, with a slope of $-4.68 \mathrm{eV} / \mathrm{mm}$ that was determined by a linear fitting procedure (Fig. 7). This value is in excellent agreement with the value of $-4.62 \mathrm{eV} / \mathrm{mm}$ calculated from the dispersion equation [Eq. (5)] for $\Theta_{B}=38.67^{\circ}$. This equation is derived from the Bragg equation when the detector is oriented perpendicularly to the (central) direction of the diffracted photons, namely,

$$
\frac{d E}{d z}=-\frac{E \times \cos \left(\Theta_{B}\right)}{2 R} .
$$

\section{CONCLUSION}

A new von Hamos spectrometer combining the HAPG crystal and a microchannel plate-based detector working in the energy range of $2-5 \mathrm{keV}$ (at the first order of reflection) has been built and successfully commissioned using synchrotron radiation (GALAXIES beamline, SOLEIL synchrotron). A resolving power $\mathrm{E} / \Delta \mathrm{E}$ of 4000 has been achieved with an energy window of $75 \mathrm{eV}$ at a Bragg angle of $38^{\circ}$. It will allow for studies in an energy range that has been rarely explored.

The success of using an HAPG crystal in a von Hamos configuration encouraged us to move toward the construction of a multicrystal (up to 9) version of the spectrometer. The total efficiency of the new spectrometer will be one order of magnitude higher than the spectrometer presented in this paper. 


\section{ACKNOWLEDGMENTS}

Measurements were performed at the GALAXIES beamline of the SOLEIL Synchrotron, France. We are grateful to J.-P. Rueff for the help during the measurements and to SOLEIL staff for smoothly running the facility. The authors are also grateful to the ASUR group of the Institut des NanoSciences de Paris for the loan of experimental equipment during the development of the experimental setup and for helpful discussions. D.K. wishes to acknowledge support from LabEx MiChem, France. This work was performed within the LABEX Plas@Par project supported by Grant No. 11-IDEX0004-02 from Agence Nationale de la Recherche.

\section{DATA AVAILABILITY}

The data that support the findings of this study are available from the corresponding author upon reasonable request.

\section{REFERENCES}

${ }^{1}$ R. Bohinc, M. Żitnik, K. Bučar, M. Kavčič, S. Carniato, L. Journel, R. Guillemin, T. Marchenko, E. Kawerk, M. Simon, and W. Cao, J. Chem. Phys. 144, 134309 (2016).

${ }^{2}$ T. Marchenko, S. Carniato, L. Journel, R. Guillemin, E. Kawerk, M. Żitnik, M. Kavčič, K. Bučar, R. Bohinc, M. Petric, V. Vaz da Cruz, F. Gel'mukhanov, and M. Simon, Phys. Rev. X 5, 031021 (2015).

${ }^{3}$ D. Céolin, T. Marchenko, R. Guillemin, L. Journel, R. K. Kushawaha, S. Carniato, S.-M. Huttula, J. P. Rueff, G. B. Armen, M. N. Piancastelli, and M. Simon, Phys. Rev. A 91, 022502 (2015).

${ }^{4}$ C. Bomme, R. Guillemin, T. Marin, L. Journel, T. Marchenko, D. Dowek, N. Trcera, B. Pilette, A. Avila, H. Ringuenet, R. K. Kushawaha, and M. Simon, Rev. Sci. Instrum. 84, 103104 (2013).

${ }^{5}$ M. Simon, R. Püttner, T. Marchenko, R. Guillemin, R. K. Kushawaha, L. Journel, G. Goldsztejn, M. N. Piancastelli, J. M. Ablett, J.-P. Rueff, and D. Céolin, Nat. Commun. 5, 4069 (2014).

${ }^{6}$ R. Guillemin, S. Sheinerman, R. Püttner, T. Marchenko, G. Goldsztejn, L. Journel, R. K. Kushawaha, D. Céolin, M. N. Piancastelli, and M. Simon, Phys. Rev. A 92, 012503 (2015).

${ }^{7}$ F. Bloch and P. A. Ross, Phys. Rev. 47, 884 (1935).

${ }^{8}$ B. Rudek, S. Son, D. Rolles et al., Nat. Photonics 6, 858 (2012).

${ }^{9}$ M. Kavcic, M. Zitnik, K. Bucar, A. Mihelic, B. Marolt, J. Szlachetko, P. Glatzel, and K. Kvashnina, Phys. Rev. B 87, 075106 (2013).

${ }^{10}$ J. Szlachetko, C. J. Milne, J. Hoszowska, J.-C. Dousse, W. Błachucki, J. Sa, Y. Kayser, M. Messerschmidt, R. Abela, S. Boutet, C. David, G. Williams, M. Pajek, B. D. Patterson, G. Smolentsev, J. A. van Bokhoven, and M. Nachtegaal, Struct. Dyn. 1, 021101 (2014).

${ }^{11}$ H. H. Johann, Z. Phys. 69(3), 185 (1931).

${ }^{12}$ T. Johansson, Z. Phys. 82, 507 (1933).

${ }^{13}$ L. v. Hámos, Naturwissenschaften 20, 705 (1932).
${ }^{14}$ A. C. Hudson, W. C. Stolte, D. W. Lindle, and R. Guillemin, Rev. Sci. Instrum. 78, 053101 (2007).

${ }^{15}$ M. Kavčič, M. Budnar, A. Mühleisen, F. Gasser, M. Żitnik, K. Bučar, and R. Bohinc, Rev. Sci. Instrum. 83, 069901 (2012).

${ }^{16}$ R. Alonso-mori, J. Kern, D. Sokaras, T.-C. Weng, D. Nordlund, R. Tran, J. Delor, V. K. Yachandra, J. Yano, U. Bergmann, R. Alonso-mori, J. Kern, D. Sokaras, T. Weng, D. Nordlund, R. Tran, P. Montanez, J. Delor, and V. K. Yachandra, Rev. Sci. Instrum. 83, 073114 (2012).

${ }^{17}$ J. Hoszowska, J.-C. Dousse, J. Kern, and C. Rhême, Nucl. Instrum. Methods Phys. Res., Sect. A 376, 129 (1996).

${ }^{18}$ L. C. Jarrott, M. S. Wei, C. McGuffey, F. N. Beg, P. M. Nilson, C. Sorce, C. Stoeckl, W. Theoboald, H. Sawada, R. B. Stephens, P. K. Patel, H. S. Mclean, O. L. Landen, S. H. Glenzer, and T. Döppner, Rev. Sci. Instrum. 88, 043110 (2017).

${ }^{19}$ M. S. D. Río and R. Dejus, Proc. SPIE 8141, 814115 (2011).

${ }^{20}$ U. Zastrau, A. Woldegeorgis, E. Forster, R. Loetzsch, H. Marschner, and I. Uschmann, J. Instrum. 8, P10006 (2013).

${ }^{21}$ M. Gerlach, L. Anklamm, A. Antonov, I. Grigorieva, I. Holfelder, B. Kanngießer, H. Legall, W. Malzer, C. Schlesiger, and B. Beckhoff, J. Appl. Crystallogr. 48, 1381 (2015).

${ }^{22}$ T. R. Preston, S. Göde, J.-P. Schwinkendorf, K. Appel, E. Brambrink, V. Cerantola, H. Höppner, M. Makita, A. Pelka, C. Prescher, K. Sukharnikov, A. Schmidt, I. Thorpe, T. Toncian, A. Amouretti, D. Chekrygina, R. W. Falcone, K. Falk, L. B. Fletcher, E. Galtier, M. Harmand, N. J. Hartley, S. P. Hau-Riege, P. Heimann, L. G. Huang, O. S. Humphries, O. Karnbach, D. Kraus, H. J. Lee, B. Nagler, S. Ren, A. K. Schuster, M. Smid, K. Voigt, M. Zhang, and U. Zastrau, J. Instrum. 15, P11033 (2020).

${ }^{23}$ J.-M. Tarascon, in Plenary Lecture at the HAXPES Conference Paris, 2-7 June 2019.

${ }^{24}$ I. Grigorieva, A. Antonov, and G. Gudi, Condens. Matter 4, 18 (2019).

${ }^{25}$ L. Anklamm, C. Schlesiger, W. Malzer, D. Grötzsch, M. Neitzel, and B. Kanngießer, Rev. Sci. Instrum. 85, 053110 (2014).

${ }^{26}$ I. Ismail, L. Journel, R. Vacheresse, J. Palaudoux, T. Marin, F. Penent, F. Penent, and M. Simon, Rev. Sci. Instrum. 89, 113101 (2018).

${ }^{27}$ C. Prigent, "L'émission X: Un Outil et Une Sonde Pour l'interaction LaserAgrégats," Ph.D. thesis (Université Pierre et Marie Curie, 2004).

${ }^{28}$ H. Yava, E. E. Alp, H. Sinn, and R. Khachatryan, AIP Conf. Proc. 789, 299 (2005).

${ }^{29}$ S. Hayakawa, A. Yamaguchi, W. Hong, Y. Gohshi, T. Yamamoto, K. Hayashi, J. Kawai, and S. Goto, Spectrochim. Acta, Part B 54, 171 (1999).

${ }^{30}$ J.-P. Rueff, J. M. Ablett, D. Céolin, D. Prieur, T. Moreno, V. Balédent, B. Lassalle-Kaiser, J. E. Rault, M. Simon, and A. Shukla, J. Synchrotron Radiat. 22, 175 (2015).

${ }^{31}$ U. Zastrau, C. R. D. Brown, T. Döppner, S. H. Glenzer, G. Gregori, H. J. Lee, H. Marschner, S. Toleikis, O. Wehrhan, and E. Förster, J. Instrum. 7, P09015 (2012).

${ }^{32}$ B. Abraham, S. Nowak, C. Weninger, R. Armenta, J. Defever, D. Day, G. Carini, K. Nakahara, A. Gallo, S. Nelson, D. Nordlund, T. Kroll, M. S. Hunter, T. van Driel, D. Zhu, T.-C. Weng, R. Alonso-Mori, and D. Sokaras, J. Synchrotron Radiat. 26, 629 (2019).

${ }^{33}$ J. Kawai, C. Satoko, and Y. Gohshi, J. Phys. C: Solid State Phys. 20, 69 (1987).

${ }^{34}$ M. O. Krause and J. H. Oliver, J. Phys. Chem. Ref. Data 8, 329 (1979). 